\title{
Bir diş hekimliği fakültesindeki konik ışınlı bilgisayarlı tomografi incelemesi istenme nedenleri
}

\author{
Zühre Akarslan, * İkay Peker \\ Ağız, Diş ve Çene Radyolojisi Anabilim Dalı, \\ Gazi Üniversitesi Diş Hekimliği Fakültesi, Ankara, Türkiye
}

\section{ÖZET}

AmAÇ: Konik ışınlı bilgisayarlı tomografi (KIBT) dental ve maksillofasiyal dokuların üç boyutlu görüntülenmesini sağlayan bir radyografik tekniktir. Son yıllarda bu tekniğin ülkemizde kullanımı artarak devam etmektedir. Bu çalışmanın amacı bir diş hekimliği fakültesinin Ağız, Diş ve Çene Radyolojisi Anabilim Dalında KIBT istenme nedenleri ve bunların dağılımının belirlenmesidir.

Gereç VE YönTem: Çalışmada Gazi Üniversitesi Diş Hekimliği Fakültesi Ağız, Diş ve Çene Radyolojisi Anabilim Dalında KIBT elde edilmesi için başvuran hastalara ait 1087 adet KIBT istek formu incelendi. İncelemenin bölgesi ve nedeni çalışma için hazırlanan standart formlara kaydedildi.

BULGULAR: KIBT isteklerinin sırasıyla: implant planlaması (\%42.04), çene lezyonları (\%18.31), üçüncü molar dişlerin köklerinin mandibular kanal ile olan ilişkisi (\% 11.13), gömülü dişlerin lokalizasyonu ve komşu anatomik yapılarla olan ilişkisi (\%7.82), temporomandibular eklem patolojileri (\%3.13), sinüs patolojileri (\%3.13), çene ve diş fraktürleri (\%2.94), alveol kemiğinin kalite ve kantite değerlendirmesi (\%1.93), dudak damak yarığı (\%1.20) ve diğer nedenler (\%8.37) için olduğu görüldü.

SoNuç: Çalışmanın sonuçları KIBT incelemesinin en fazla implant planlaması için istendiğini gösterdi.

Anahtar Kelimeler: Diş implantı; konik ışınlı bilgisayarlı tomografi; radyografi

KaynaK Göstermek İçin: Akarslan Z, Peker İ. Bir diş hekimliği fakültesindeki konik ışınlı bilgisayarlı tomografi incelemesi istenme nedenleri. Acta Odontol Turc 2015;32(1):1-6

YAYıN HAKKI: @ 2015 Akarslan ve Peker. Bu eserin yayın hakkı Creative Commons Attribution License ile ruhsatlandırılmıştır. Sınırsız kullanım, dağıtım ve her türlü ortamda çoğaltım, yazarlar ve kaynağın belirtilmesi kaydıyla serbesttir.

[Abstract in English is at the end of the manuscript]

Makale gönderiliş tarihi:12 Şubat 2014; Yayına kabul tarihi: 21 Mayıs 2014 *iletişim: Zühre Akarslan, Ağız, Diş ve Çene Radyolojisi Anabilim Dalı, Gazi Üniversitesi Diş Hekimliği Fakültesi, 82. Sokak, 06510, Emek, Ankara, Türkiye; e-posta: dtzuhre@yahoo.com
Giriş

Konik ışınlı bilgisayarlı tomografi (KIBT), 90'lı yılların sonunda konik ışın tekniğine dayalı geliştirilmiş bir sistem olup, maksillofasiyal yapıların üç boyutlu görüntülenmesine olanak sağlamaktadır. ${ }^{1}$

KIBT tekniği radyografik görüntülemede birçok avantaj bulundursa $\mathrm{da}^{2}$ radyografik uygulamalardaki temel prensip görüntülenecek bölgenin mümkün olan en düşük radyasyon dozu kullanılarak görüntülenmesinin gerekliliğidir. Buna göre radyografik bilginin, hastalığın teşhis ve tedavisinde sağlayacağı yarar, x-ışınının zararına göre daha fazla ise radyografi uygulanmalıdır. $\mathrm{Bu}$ bakış açısı, kullanılacak radyografik tekniğin belirlenmesi için de geçerlidir. Optimal radyografik bilgiyi sağlayan en düşük radyasyon dozu kullanılan teknik seçilmelidir. ${ }^{3}$ Dünyada birçok merkezde olduğu gibi, ülkemizdeki diş hekimliği fakültelerinde, ağız-diş sağlığı merkezlerinde ve özel görüntüleme merkezlerinde KIBT kullanımı her geçen gün artmaktadır. Bu nedenle de tekniğin kullanım alanları iyi bilinmelidir. ${ }^{4}$

KIBT'nin, birçok durum için geleneksel iki boyutlu görüntülerden daha üstün olduğu gösterilmiştir. ${ }^{5}$ Tekniğin dental implant operasyonu ve ortodontik tedavi öncesi değerlendirmede, gömülü dişlerin, yabancı cisimlerin ve süpernümerer dişlerin uzaysal konumları ve anatomik yapılarla ilişkisinin belirlenmesinde, mandibular kondil ve çevre kemik yapıların incelenmesinde kullanılabileceği bildirilmiştir. ${ }^{2}$ Ayrıca, kök sayı anomalisi, dilaserasyon, ve dens in dente gibi anomali bulunan dişlerde endodontik tedavi öncesinde kullanılması önerilmiştir.6,7

Klinik pratikte KIBT'nin, hekimler tarafından istenme nedenlerinin değerlendirilmesi, KIBT'nin kullanım alanlarının belirlenerek, tekniğin geliştirilmesi açısından yarar sağlayabilir. Bu çalışmanın amacı, bir diş hekimliği fakültesine çeşitli nedenlerle başvuran ve KIBT görüntüleri elde edilen hastalardaki KIBT istenme nedenlerini, tetkik istek formlarını incelenerek retrospektif olarak değerlendirmektir.

\section{Gereç Ve Yöntem}

Çalışma öncesinde Ankara Üniversitesi Diş Hekimliği Fakültesi Etik Kurulundan onay alındı. Çalışmada, Gazi Üniversitesi Diş Hekimliği Fakültesi Ağız, Diş ve Çene 
Radyolojisi Anabilim Dalı, KIBT arşivinde yer alan 2012 yılındaki 1087 hastaya ait inceleme istek formları retrospektif olarak değerlendirildi. Bu istekler, fakültedeki klinikler, diğer diş hekimliği fakülteleri, çeşitli hastaneler, özel muayenehaneler, ağız ve diş sağlığı merkezlerinden yapılmıştı. İncelenmesi istenen bölgeler ve istek nedenleri çalışma için hazırlanan standart formlara kaydedildi (Tablo 1). Elde edilen veriler tanımlayıcı istatistik yöntemi ile değerlendirildi.

\section{BULGULAR}

Toplam 1087 istek formu incelendi ve 36 farklı KIBT istek nedeni olduğu belirlendi. Bu nedenlerden 25 'i $\% 10$ 'dan daha düşük bir oranı oluşturduğu için "diğer nedenler" başlı̆̆ı alıında birleştirildi.
Tetkiklerin en fazla implant planlaması için istendiği saptandı (\%42.04). Bunu, çene kemiklerindeki lezyonlar (\%18.31), mandibular 3. molar dişlerin mandibular kanal ile olan ilişkisi (\%11.13) ve diğer nedenler (\%8.37) izlemekteydi (Tablo 2). Diğer nedenler arasında en fazla post-operatif implant görüntülenmesi (\%9.89) ve preoperatif sinüs lifting (\%9.89) işlemi bulunmaktaydı (Tablo 3).

KIBT'nin implant planlamasında en fazla maksilla ve mandibulanın birlikte görüntülenmesi (\%36.33), en az olarak da mandibulanın anterior bölgesi (\%3.50) için istendiği belirlendi (Tablo 4). Lezyonların incelenmesi amacıyla istenen KIBT görüntülerinin en fazla mandibulanın posterior bölgesi (\%47.77), en az ise maksilla ve mandibulanın birlikte değerlendirilmesi (\%4.02) için istendiği saptandı (Tablo 5). Gömülü dişlerin incelenmesi

Tablo 1. Çalışmada kullanılan form

\begin{tabular}{l}
\hline KIBT incelemesi istek nedenleri \\
\hline Pre-operatif implant planlaması \\
Lezyon/lezyonların değerlendirilmesi \\
Mandibular 3. molar diş köklerinin mandibular kanal ile ilişkisinin değerlendirilmesi \\
Gömülü dişlerin (3. molar hariç) lokalizasyonu ve anatomik yapıllarla ilişkisinin değerlendirilmesi \\
TME patolojlerinin değerlendirilmesi \\
Paranazal sinüs patolojilerinin değerlendirilmesi \\
Travma geçirmiş hastaların fraktür yönünden değerlendirilmesi \\
Pre-operatif alveol kemiği rezorpsiyonunun değerlendirilmesi \\
Dudak-damak yarığının değerlendirilmesi \\
\hline Diğer \\
\hline İnceleme istenen bölge/bölgeler \\
\hline Maksilla: maksilla anterior, maksilla posterior, maksilla anterior ve posterior, \\
Mandibula: mandibula anterior, mandibula posterior, mandibula anterior ve posterior, \\
\hline Maksilla ve mandibula \\
Maksillofasiyal bölge \\
Mandibula ve maksillofasiyal bölge \\
\hline
\end{tabular}

Tablo 2. KIBT incelemesi istek nedenlerinin genel dağılımı

\begin{tabular}{lcc}
\hline KIBT incelemesi istek nedenleri & N & $\%$ \\
\hline Pre-operatif implant planlaması & 457 & 42.04 \\
\hline Lezyon/lezyonların değerlendirilmesi & 199 & 18.31 \\
\hline Mandibular 3. molar diş köklerinin mandibular kanal ile ilişkisinin değerlendirilmesi & 121 & 11.13 \\
\hline Gömülü dişlerin (3. molar hariç) lokalizasyonu ve anatomik yapılarla ilişkisinin değerlendirilmesi & 85 & 7.82 \\
\hline TME patolojilerinin değerlendirilmesi & 34 & 3.13 \\
\hline Paranazal sinüs patolojilerinin değerlendirilmesi & 34 & 3.13 \\
\hline Travma geçirmiş hastaların fraktür yönünden değerlendirilmesi & 32 & 2.94 \\
Pre-operatif alveol kemiği rezorpsiyonunun değerlendirilmesi & 21 & 1.93 \\
\hline Dudak-damak yarı̆̆ının değerlendirilmesi & 13 & 1.20 \\
Diğer & 91 & 8.37 \\
\hline Toplam & 1087 & 100 \\
\hline
\end{tabular}


Tablo 3. "Diğer" başlığı altında değerlendirilen KIBT incelemesi istek nedenleri

\begin{tabular}{|c|c|c|}
\hline KIBT incelemesi istek nedenleri & $\mathbf{N}$ & $\%$ \\
\hline Post-operatif implant değerlendirmesi & 9 & 9.89 \\
\hline Pre-operatif sinüs lifting işlemi & 9 & 9.89 \\
\hline Post-operatif lezyon cerrahisi değerlendirilmesi & 8 & 8.79 \\
\hline Diş kökü-alveol kemiği ilişkisinin değerlendirilmesi & 7 & 7.69 \\
\hline Sürmüş dişlerin ö̈klerinin maksiler sinüsle ilişkisinin değerlendirilmesi & 6 & 6.59 \\
\hline Pre-operatif ortognatik cerrahi & 5 & 5.49 \\
\hline Post-operatif ortognatik cerrahi & 5 & 5.49 \\
\hline Maksiller 3. molar dişlerin değerlendirilmesi & 5 & 5.49 \\
\hline Apeksifikasyon tedavisinin değerlendirilmesi & 4 & 4.41 \\
\hline Kök artık/artıklarının değerlendirilmesi & 4 & 4.41 \\
\hline Post-operatif travma kontrolü & 3 & 3.30 \\
\hline Yumuşak doku şişliklerinin değerlendirilmesi & 3 & 3.30 \\
\hline Periapikal lezyon/lezyonların değerlendirilmesi & 3 & 3.30 \\
\hline Alveolar kemik rezorpsiyon tedavisinin kontrolü & 2 & 2.20 \\
\hline Osteonekroz bölgesinin değerlendirilmesi & 2 & 2.20 \\
\hline Fasiyal ağrı & 2 & 2.20 \\
\hline Postoperatif enfeksiyonun değerlendirilmesi & 2 & 2.20 \\
\hline Apeks dışına taşmış kanal patının değerlendirilmesi & 2 & 2.20 \\
\hline İnternal rezorpsiyonun değerlendirilmesi & 2 & 2.20 \\
\hline Fasiyo-dento-alveolar anomalinin değerlendirilmesi & 2 & 2.20 \\
\hline Sialolit & 2 & 2.20 \\
\hline Post-operatif apikal rezeksiyon değerlendirilmesi & 1 & 1.09 \\
\hline Stilohyoid ligament kalsifikasyonunun değerlendirilmesi & 1 & 1.09 \\
\hline Dental füzyon değerlendirilmesi & 1 & 1.09 \\
\hline Dental servikal erozyon değerlendirilmesi & 1 & 1.09 \\
\hline Toplam & 91 & 100 \\
\hline
\end{tabular}

için en fazla maksilladan (\%51.76) en az da maksilla ve mandibulanın birlikte olduğu vakalar için (\%14.12) istek yapıldığı belirlendi (Tablo 6). Travma geçirmiş hastalarda ise en fazla mandibuladan (\%65.62) istek yapıldığı saptandı (Tablo 7).

\section{TARTIŞMA}

Çalışmada KIBT isteklerinin çoğunlukla implant planlaması için yapıldığı belirlendi. Bu sonuç KIBT'nin, implant planlamasında önemli bir yeri olduğunu göstermektedir. Amerikan Oral ve Maksillofasiyal Radyoloji Akademisi (AOMR) tarafından 2000 yılında, dental implant tedavi planlamasındaki kesitsel görüntülemenin önemi vurgulanmış, bunun için geleneksel tomografi tekniğinin kullanılabileceği bildirilmiştir. ${ }^{8}$ Bununla beraber, bu yöntemde radyoopak stent gerekliği, tek dental arkın birkaç dişlik kısıtlı bir alanının görüntülenmesi ve ilgili alan dışındaki görüntülerin bulanıklaşması nedeniyle çevre dokuların net izlenememesi gibi dezavantajları olduğu belirtilmektedir. ${ }^{9-11}$ AOMR, 2012 yılında yayınladığı makalede ise bu görüşü desteklemiş ve son yıllarda yaygın olarak kullanılan KIBT tekniğini önermiştir. ${ }^{12}$
Tablo 4. Pre-operatif implant planlaması için istenen KIBT incelemesinin bölgesel dağılımı

\begin{tabular}{lcc}
\hline Pre-operatif implant planlaması & & \\
\hline Bölge & N & $\%$ \\
Maksilla anterior & 31 & 6.78 \\
Maksilla posterior & 100 & 21.88 \\
Maksilla anterior ve posterior & 26 & 5.69 \\
Mandibula anterior & 16 & 3.50 \\
Mandibula posterior & 83 & 18.16 \\
Mandibula anterior ve posterior & 35 & 7.66 \\
Maksilla ve mandibula & 166 & 36.33 \\
Toplam & 457 & 100 \\
\hline
\end{tabular}

KIBT'nin, diş hekimleri tarafından, özellikle implant planlaması amacıyla kullanıldığı bildirilmiştir. ${ }^{4}$ Bununla birlikte, radyasyonun zararlı etkilerinden dolayı birden fazla implant yerleştirilecek vakalarda kullanılması önerilmektedir. ${ }^{13}$

KIBT görüntülerinin, intraoral radyografi görüntülerinden daha düşük çözünürlükte olması nedeniyle, implant çevresi ve marjinal alveolar kemikte meydana 
Tablo 5. Lezyonların değerlendirilmesi için istenen KIBT incelemelerinin bölgesel dağılımı

\begin{tabular}{lcc}
\hline Lezyonlar & N & $\%$ \\
\hline Bölge & 20 & 10.05 \\
Maksilla anterior & 35 & 17.59 \\
Maksilla posterior & 9 & 4.52 \\
Maksilla anterior ve posterior & 20 & 10.05 \\
Mandibula anterior & 95 & 47.74 \\
Mandibula posterior & 12 & 6.03 \\
Mandibula anterior ve posterior & 8 & 4.02 \\
Maksilla ve mandibula & 199 & 100 \\
\hline Toplam & &
\end{tabular}

Tablo 6. Gömülü dişlerin değerlendirilmesi için istenen KIBT incelemelerinin bölgesel dağılımı

\begin{tabular}{lcc}
\hline Gömülü Dişler & & \\
\hline Bölge & N & $\%$ \\
Maksilla & 44 & 51.76 \\
Mandibula & 29 & 34.12 \\
Maksilla ve mandibula & 12 & 14.12 \\
Toplam & 85 & 100 \\
\hline
\end{tabular}

Tablo 7. Travma geçirmiş hastalarda fraktür değerlendirilmesi için istenen KIBT incelemelerinin bölgesel dağııımı

\begin{tabular}{lcc}
\hline \multicolumn{3}{l}{ Travma geçirmiş hastalarda fraktür yönünden inceleme } \\
\hline Bölge & $\mathrm{N}$ & $\%$ \\
Maksilla & 1 & 3.13 \\
Mandibula & 21 & 65.62 \\
Maksillofasiyal & 9 & 28.12 \\
Mandibula ve maksillofasiyal & 1 & 3.13 \\
Toplam & 32 & 100 \\
\hline
\end{tabular}

gelen küçük değişikliklerin değerlendirilmesi için uygun olmadığı bildirilmiştir. ${ }^{12}$ Aynı zamanda, titanyum implantlara bağlı olarak oluşan artifaktlar nedeniyle, implantların post-operatif takibinde klinik olarak asemptomatik vakalarda periapikal radyografların kullanılması önerilmektedir. ${ }^{12}$ Öte yandan, post-operatif dönemde implantta mobilite ve/veya his değişikliği bulunan vakalarda ilgili bölgenin kesitlerle görüntülenmesi ve bunun geleneksel tomografi veya KIBT ile yapılabileceği belirtilmektedir. ${ }^{12} \mathrm{Bu}$ çalışmada, post-operatif implant değerlendirilmesi için istek yapılan tetkik sayısının az olduğu saptandı.

KIBT tekniği ile çene kemiklerinde izlenen kist, tümör ve benzeri lezyonların boyutları, komşu anatomik yapılarla olan ilişkileri ve kortikal kemikte neden olduğu deği- şiklikler belirlenebilmektedir. ${ }^{2}$ Lezyonların radyografik incelenmesi amacıyla istenen KIBT oranının implant planlamasına göre daha az olduğu saptanmakla birlikte, istek nedenleri kategorisinde ikinci sırada olduğu belirlendi.

KIBT görüntüleri mandibular 3. molar dişlerin mandibular kanal ile olan ilişkisinin değerlendirilmesinde rutin olarak değil, sadece geleneksel tekniklerde diş köklerinin mandibular kanal kortikal sınırında kesinti izlendiğinde ve ilgili diş köklerinin mandibular kanal üzerine süperpoze olduğu durumlarda gerekli olduğu belirtilmektedir. ${ }^{14,15}$ Gömülü dişlerin pozisyonu ve komşu anatomik yapılarla olan ilişkilerin belirlenmesi cerrahi işlemler esnasında oluşabilecek komplikasyonların en aza indirilmesi açısından önemlidir. ${ }^{2}$ Bu çalışmada mandibular üçüncü molar dişlerin mandibular kanal ile ilişkisinin belirlenmesi için yapılan KIBT isteklerinin, implant planlaması ve lezyonların değerlendirilmesinden sonra üçüncü sırada yer aldığı saptandı. Bunu, diğer gömülü dişlerin lokalizasyonları ve çevre anatomik yapılarla ilişkilerinin değerlendirilmesi takip etmekteydi.

KIBT, temporomandibuler eklemin (TME) kemik yüzeylerindeki düzleşme, erozyon, fraktür, osteofit, ankiloz, gelişimsel anomaliler, osteoartrit, ve juvenil idiopatik artritin teşhisi için kullanılabilir. ${ }^{16}$ Bununla birlikte, diske bağlı patolojilerin incelenmesi için manyetik rezonans görüntüleme kullanıımalıdır. ${ }^{17} \mathrm{Bu}$ çalışmada, TME'nin görüntülenmesi için yapılan KIBT istek sayısının az olduğu belirlendi.

Paranazal sinüs patolojileri kronik orofasiyal ağrıya neden olabilmektedir. Özellikle maksiller sinüslerde meydana gelen mukozal kalınlaşma, atipik odontalji ve TME ağrısını taklit edebilmektedir. ${ }^{18}$ Endodontik tedavi görmüş bireylerde, periodontitisli hastalarda, çürük ve devital dişlere komşu maksiller sinüste mukozal kalınlaşma gelişebilmekte ve KIBT ile teşhis edilebilmektedir. ${ }^{19} \mathrm{Bu}$ teknik ayrıca odontojenik kökenli maksiller sinüzitin teşhisinde geleneksel radyograflara göre daha başarılıdır. ${ }^{20}$ Bununla birlikte, bu çalışmada geniş görüntüleme alanına sahip bir cihaz ile görüntü elde edilmesine rağmen, sinüs patolojileri için yapılan KIBT isteklerinin az sayıda olduğu belirlendi.

KIBT, dental ve alveolar kemik fraktürlerinin teşhisi için kullanılabilmesine rağmen. kranio-serebral travma ve birden fazla kırık şüphesi olan durumlarda kullanımı uygun değildir. ${ }^{17}$ Maksillofasiyal fraktürlerin teşhisinde medikal bilgisayarlı tomografi altın standart olarak kabul edilmektedir. ${ }^{21}$ Literatürde KIBT'nin panoramik rekonstrüksiyonunda sekonder yapıların süperpozisyonu olmadığından, fraktürlerin değerlendirilmesinde, cerrahlar tarafından geleneksel panoramik radyograf yerine tercih edildiği de bildirilmiştir. ${ }^{22} \mathrm{Bu}$ çalışmada travma geçirmiş hastalarda KIBT isteklerinin az sayıda olduğu ve bu isteklerin en fazla mandibulanın görüntülenmesi için yapıldığı belirlendi. 
KIBT'nin, ortodontide kraniyofasiyal morfoloji, hava yolu açıklığı ve dental gelişimin incelenmesinde kullanılabileceği bildirilmiştir. ${ }^{23}$ Aynı zamanda, gömülü dișlerin yerlerinin belirlenmesi, sürme gecikmesi, ileri derecede kök rezorpsiyonu ve iskeletsel patoloji olan durumlarda kullanılması önerilmektedir. ${ }^{23} \mathrm{Bu}$ çalışmada KIBT'nin genellikle dudak yarığı vakalarında istendiği, çok az sayıda olmak üzere de, diş kökü ile alveol kemiği ilişkisi, ve ortognatik cerrahi için kullanıldığı belirlendi. Bununla birlikte, ortodontik tedavi sürecindeki bireyler çoğunlukla çocukluk ve ergenlik dönemindedir ve radyasyona yetişkinlerden daha duyarlıdır. Dolayısıyla, ortodontik amaçlı KIBT isteği yapılırken, bu durum göz önünde bulundurulmalıdır. ${ }^{24}$

KIBT'nin, apikal cerrahi öncesinde periapikal lezyonların değerlendirilmesinde, kök kırıkları ve kök kanal anatomisinin incelenmesinde kullanılabileceği bildirilmiştir. ${ }^{25}$ Ayrıca kök sayı anomalisi, dilaserasyon ve dens in dente gibi anomali bulunan vakalarda tedavinin başarısını artırdığı bulunmuştur. ${ }^{6,7}$ Bununla birlikte, bazı dental materyaller (kanal patı, güta-perka, post vidası, vb.) artifakta neden olarak kök kanallarının radyografik incelenmesini olumsuz yönde etkileyebilmektedir. ${ }^{26}$ KIBT'nin, kök kırıklarının teşhisindeki etkinliği araştııımış ve yapay olarak oluşturulmuş ve güta perka ile doldurulmuş kök kırı̆ğı bulunan dişlerde oluşan artifakt nedeniyle periapikal radyograflarla aralarında fark olmadığı bildirilmiştir. ${ }^{27} \mathrm{Bu}$ çalışmada periapikal lezyonlar, apeks dışına taşmış kanal patı, internal rezorpsiyon, servikal erozyon ve post-operatif apikal rezeksiyon için az sayıda KIBT isteğinin yapıldığı saptandı. Bu sonuç, tekniğin endodontik tedavi ve periapikal lezyonların teşhisi için rutin olarak kullanılmadığını göstermektedir.

KIBT görüntülerinin periodontal patolojiler ve çürük teşhisindeki etkinliği çeşitli çalışmalarda incelenmiştir. KIBT'nin alveolar kemikteki krater ve furkasyon defektlerinin belirlenmesinde intraoral dijital radyografiden daha üstün olduğu, buna karşın kemik kalitesi ve lamina duranın devamlılığının belirlenmesinde intraoral radyografinin daha üstün olduğu bildirilmiştir. ${ }^{28} \mathrm{KIBT}$ 'nin okluzal çürük teşhisinde geleneksel radyografi ve fosfor plaklara göre daha üstün olduğu, bununla birlikte ara yüz çürüklerinin teşhisinde aralarında anlamlı fark olmadığı bildirilmiştir. ${ }^{29}$ Ayrıca KIBT'nin kavitasyon oluşturmuş ara yüz çürüklerinin teşhisinde dijital intraoral tekniğine göre daha üstün olduğu saptanmıştır. ${ }^{30} \mathrm{Bu}$ nunla birlikte, görüntünün en az radyasyon dozu ile elde edilmesi gerektiği için, KIBT bu durumlar için rutin olarak kullanılacak bir yöntem değildir. Bu çalışmada da KIBT'nin periodontal defektler ve çürük teşhisi için kullanılmadığı saptandı.

Sonuç olarak, KIBT incelemesinin en fazla implant planlaması için istendiği belirlendi. KIBT istenme nedenlerinin değerlendirilmesi, en fazla ve en az kullanıldığı alanların belirlenmesi, tekniğin avantaj ve dezavantajlarının ortaya konulmasına katkı sağlayarak önümüzdeki yıllarda teknik açıdan daha donanımlı cihazların geliştirilmesi için teşvik edici olabilir.

Çıkar çatışması: Yazarlar bu çalışmayla ilgili herhangi bir çıkar çatışmalarının bulunmadığını bildirmişlerdir.

\section{KAYNAKLAR}

1. Mozzo P, Procacci C, Tacconi A, Martini PT, Andreis IA. A new volumetric CT machine for dental imaging based on the cone-beam technique: preliminary results. Eur Radiol 1998;8:1558-64.

2. Scarfe WC. Farman AG. Cone-beam computed tomography. White SC, Pharoah MJ, eds. Oral raiology principles and interpretation. St. Louis, MO: Mosby-Elsevier; 2009. p.225-43.

3. Dawood A, Patel S, Brown J. Cone beam CT in dental practice. $\mathrm{Br}$ Dent J 2009;207:23-8.

4. Horner K. Cone-beam computed tomography: time for an evidencebased approach. Prim Dent J 2013;2:22-31.

5. Adibi S, Zhang W, Servos T, O'Neill PN. Cone beam computed tomography in dentistry: what dental educators and learners should know. J Dent Educ 2012;76:1437-42.

6. Cotton TP, Geisler TM, Holden DT, Schwartz SA, Schindler WG. Endodontic applications of cone-beam volumetric tomography. J Endod 2007;33:1121-32.

7. Patel S, Dawood A, Mannocci F, Wilson R, Pitt Ford T. Detection of periapical bone defects in human jaws using cone beam computed tomography and intraoral radiography. Int Endod J 2009;42:507-15.

8. Tyndall DA, Brooks SL. Selection criteria for dental implant site imaging: a position paper of the American Academy of Oral and Maxillofacial radiology. Oral Surg Oral Med Oral Pathol Oral Radiol Endod 2000;89:630-7.

9. Perez LA, Brooks SL, Wang HL, Eber RM. Comparison of linear tomography and direct ridge mapping for the determination of edentulous ridge dimensions in human cadavers. Oral Surg Oral Med Oral Pathol Oral Radiol Endod 2005;99:748-54.

10. Peker I, Alkurt MT, Michcioglu T. The use of 3 different imaging methods for the localization of the mandibular canal in dental implant planning. Int J Oral Maxillofac Implants 2008;23:463-70.

11. Kassebaum DK, Nummikoski PV, Triplett RG, Langlais RP. Crosssectional radiography for implant site assessment. Oral Surg Oral Med Oral Pathol 1990;70:674-8.

12. Tyndall DA, Price JB, Tetradis S, Ganz SD, Hildebolt C, Scarfe WC. Position statement of the American Academy of Oral and Maxillofacial Radiology on selection criteria for the use of radiology in dental implantology with emphasis on cone beam computed tomography. Oral Surg Oral Med Oral Pathol Oral Radiol 2012;113:817-26.

13. Hatcher DC, Dial C, Mayorga C. Cone beam CT for pre-surgical assessment of implant sites. J Calif Dent Assoc 2003;31:825-33.

14. Neves FS, Souza TC, Almeida SM, Haiter-Neto F, Freitas DQ, Bóscolo FN. Correlation of panoramic radiography and cone beam CT findings in the assessment of the relationship between impacted mandibular third molars and the mandibular canal. Dentomaxillofac Radiol 2012;41:553-7.

15. Ghaeminia H, Meijer GJ, Soehardi A, Borstlap WA, Mulder J, Bergé SJ. Position of the impacted third molar in relation to the mandibular canal. Diagnostic accuracy of cone beam computed tomography compared with panoramic radiography. Int $\mathrm{J}$ Oral Maxillofac Surg 2009;38:964-71.

16. Krishnamoorthy $B$, Mamatha N, Kumar VA. TMJ imaging by CBCT: Current scenario. Ann Maxillofac Surg 2013;3:80-3.

17. Kaeppler G. Applications of cone beam computed tomography in dental and oral medicine. Int J Comput Dent 2010;13:203-19. 
18. Logan GM, Brocklebank LM. An audit of occipitomental radiographs. Dentomaxillofac Radiol 1999;28:158-61.

19. Brüllmann DD, Schmidtmann I, Hornstein S, Schulze RK. Correlation of cone beam computed tomography (CBCT) findings in the maxillary sinus with dental diagnoses: a retrospective cross-sectional study. Clin Oral Investig 2012;16:1023-9.

20. Shahbazian M, Jacobs R. Diagnostic value of $2 D$ and $3 D$ imaging in odontogenic maxillary sinusitis: a review of literature. J Oral Rehabil 2012;39:294-300.

21. Scarfe WC. Imaging of maxillofacial trauma: evolutions and emerging revolutions. Oral Surg Oral Med Oral Pathol Oral Radiol Endod 2005;100 Suppl 2:S75-96.

22. MacDonald-Jankowski DS, Orpe EC. Computed tomography for oral and maxillofacial surgeons. Part 2: Cone-beam computed tomography. Asian J Oral Maxillofac Surg 2006;18:85-92.

23. Mah JK, Huang JC, Choo $\mathrm{H}$. Practical applications of cone-beam computed tomography in orthodontics. J Am Dent Assoc 2010;141 Suppl 3:7S-13S.

24. Hodges RJ, Atchison KA, White SC. Impact of cone-beam computed tomography on orthodontic diagnosis and treatment planning. Am J Orthod Dentofacial Orthop 2013;143:665-74.

25. Patel S. New dimensions in endodontic imaging: Part 2. Cone beam computed tomography. Int Endod J 2009;42:463-75.

26. Soğur E, Baksi BG, Gröndahl HG. Imaging of root canal fillings: a comparison of subjective image quality between limited cone-beam CT, storage phosphor and film radiography. Int Endod J 2007;40:179-85.

27. Patel S, Brady E, Wilson R, Brown J, Mannocci F. The detection of vertical root fractures in root filled teeth with periapical radiographs and CBCT scans. Int Endod J 2013;46:1140-52.

28. Vandenberghe B, Jacobs R, Yang J. Diagnostic validity (or acuity) of 2D CCD versus 3D CBCT-images for assessing periodontal breakdown. Oral Surg Oral Med Oral Pathol Oral Radiol Endod 2007;104:395401.

29. Kayipmaz S, Sezgin ÖS, Saricaoğlu ST, Çan G. An in vitro comparison of diagnostic abilities of conventional radiography, storage phosphor, and cone beam computed tomography to determine occlusal and approximal caries. Eur J Radiol 2011;80:478-82.

30. Wenzel A, Hirsch E, Christensen J, Matzen LH, Scaf G, Frydenberg M. Detection of cavitated approximal surfaces using cone beam CT and intraoral receptors. Dentomaxillofac Radiol 2013;42:39458105.
Reasons of cone-beam computed tomography examination requests in a dental faculty

\section{Abstract}

OBJECTIVE: Cone-beam computed tomography (СВCT) is a radiographic technique that allows the three-dimensional visualization of the dental and maxillofacial tissues. In recent years, the use of this technique in our country has been increasing continuously. The aim of this study was to assess the reasons and distribution of the CBCT requests in a Dentomaxillofacial Radiology department of a dental faculty.

Materials AND METHOD: CBCT request forms belonging to 1087 patients attending the Dentomaxillofacial Radiology department, Faculty of Dentistry, Gazi University were assessed. Information of the localization and reason of the request was recorded on a standard form prepared for the study.

RESULTS: The requested CBCT images were found to be for implant planning (42.04\%), jaw lesions (18.31\%), relationship of the mandibular canal to the roots of third molars (11.13\%), localization and relationship of impacted teeth with anatomic structures $(7.82 \%)$, temporomandibular joint pathologies $(3.13 \%)$, sinus pathologies $(3.13 \%)$, tooth and jaw fractures $(2.94 \%)$, alveolar bone quality and quantity (1.93\%), cleft lip-plate (1.20\%) and other reasons (8.37\%), in order.

ConcLusion: The results of this study showed that most of the СВСТ examinations were requested for implant planning.

KEYWORDS: Cone-beam computed tomography; dental implant; radiography 